\title{
A DNA-Peptide Fusion as a Vaccine Candidate against Breast and Ovarian Cancer Metastasis: Consequent Benefit in Certain Lung Cancers
}

CRUZ-RODRIGUEZ L..$^{1 *}$, ZIARATI P², HOCHWIMMER B. ${ }^{3}$, KAABAR M. K. A. ${ }^{4}$, BIN ZHAO. ${ }^{5}$, DILSIZ N. ${ }^{6}$, SANCHEZ BATISTA L. ${ }^{7}$, BAREA R. ${ }^{8}$, PELAEZ FIGUEROA Y. ${ }^{9}$

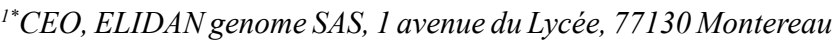
Fault Yonne, France.

${ }^{2}$ Nutrition and Food Sciences Research Center, Tehran Medical Sciences, Islamic Azad University, Tehran, Iran.

${ }^{3}$ CEO, Hochwimmer B. \& Asso. Pty Ltd, Albury, NSW, Australia.

${ }^{4}$ Department of Mathematics and Statistics, Washington State University, Pullman, WA, USA.

${ }^{5}$ School of Science, Hubei University of Technology, Wuhan, Hubei, China.

${ }^{6}$ Molecular Biology and Genetics, Faculty of Engineering and Natural Sciences, Istanbul Medeniyet University, Istanbul, Turkey.

${ }^{7}$ ExCELab Co. Ltd., Environmental Biotechnology Department, Kingston, Jamaica.

\author{
"Correspondence author \\ Prof. Dr. CRUZ-RODRIGUEZ Luis \\ CEO \\ ELIDAN genome SAS \\ 1 av du Lycée \\ 77130 Montereau FY \\ France \\ ORCID : https://orcid.org/0000-0002-7539-2382 \\ E-mail : 1cr@elidan-genome.com \\ luis.cruzrguez@gmail.com
}

Submitted : 6 Sept 2020 ; Published : 20 Sept 2020

${ }^{8}$ ELIDAN america LLC, Miami, Florida, USA.

${ }^{9}$ ELIDAN dynamic LLC, Tampa, Florida, USA.

\begin{abstract}
Cancer mortality data were obtained from the WHO Mortality Database. Lung cancer, with about 85\% being non-small cell lung cancer is one of the most common malignant tumors, considered the leading cause of cancer-related death in both men and women (associated with breast and ovarian cancer in metastasis). From published data, we designed a preventive vaccine in Silico aimed to protect against breast and ovarian cancer involved in metastasis for lung cancer. The largest increases are expected for melanoma; cancers of the prostate, kidney, liver, and urinary bladder in males; and the lung, breast, uterus, ovarian, and thyroid in females. Among all women, lung cancer mortality rates have surpassed those for breast cancer around the world. This reflects the decline of breast cancer mortality due to screening access and effective treatment alongside entrance of certain countries lifestyle and behavior in which smoking has become more prevalent in women. One aim of this research paper is to provide a better understanding for the potential dormant repositories of outbreaks and potential metastasis of breast and ovarian cancer and its consequents in lung cancer. In this study, we present to the cDNA-peptide fusion a more stable anti-tumoral against breast and ovarian cancer. As a cDNA target, we used primers from Her2 gene fusion with peptides from Her2 and human PARP-1 proteins. Our analysis identified 16 cloning DNA (cDNA) with theorical fusion stability (FS) value among 49.30-62.41 range and theorical Exosome Affinity (EA) (cDNA-peptide and exosome) among 62.60-77.10 range. We proposed a cDNA-peptide with theorical fusion value stability $F S=50.36$ Cruz and exosome affinity EA=68.02 Ro. We have named the cDNA-peptide selection as: LCR 2020_B008-55. In addition, in Silico, this cDNA-peptide also manifests partial inhibiting activity on the methylated promoter genes in lung tumors, therefore, this chimera cDNA-peptide may achieve a higher representative antitumoral activity against lung cancer disease. According to the anti-tumoral monitoring after and before vaccination using the candidate LCR 2020 B008-55, we proposed exosomes as biomarkers of lung carcinogenesis after and before vaccination. Due to the cDNA-peptides, in Silico, manifesting high affinity with exosomes, where our proposed vaccine may reach high representative activity against breast, ovarian and lung cancer in a metastasis stage, we identified this chimera with a triple antitumoral action.
\end{abstract}


Keywords: Breast Cancer, Ovarian Cancer, Metastasis, Lung Cancer, Chimera Cdna-Peptide, Theorical Fusion Value Stability (FS), Exosome Affinity (ES), Preventive Vaccine in Silico, Parp-1, Her2, Antitumoral Ler_2020_B008-55, Vaccination

\section{Introduction}

Cancer mortality data were obtained from the WHO Mortality Database. The age-standardized mortality rates, per 100,000, were calculated from 2008 to 2014 and projected for the years 2015, 2020, 2025, and 2030 [1].

Based on the published data, we have designed a preventive vaccine in Silico aimed to protect against breast and ovarian cancer involved in metastasis for lung cancer. The largest increases are expected for melanoma; cancers of the prostate, kidney, liver, and urinary bladder in males; and the lung, breast, uterus, ovarian and thyroid in females [2].

Among women, lung cancer mortality rates have surpassed those for breast cancer around the world. This reflects that the breast cancer mortality declines due to screening access and effective treatment alongside entrance of certain countries lifestyle and behavior in which smoking had become more prevalent in women [3].

Breast cancer is the second most common cancer diagnosed worldwide, affecting approximately one in eight women during their lifetime $[4,5]$.

One aim of this is to better understand potential dormant repositories of outbreaks and thereby predicate potential metastasis of breast cancer disease and its consequences in lung cancer disease [6].

Breast cancer metastasizes though the lymphatic system or via the circulatory system. Metastasses are the overwhelming cause of mortality in patients with malignancies, causing 90 $\%$ of deaths in solid tumors [7]. Metastasis in breast cancer is characterized by a distinctive spread via regional lymph nodes to the lungs, liver, brain and bones [8]. Importantly, the rates and sites of distal metastasis can vary depending on age and stage of diagnosis $[8,9]$.

The most common site of metastases is the bone, often the first site of distal metastases in up to $50 \%$ of patients [10], with lungs and liver as the second and third most common metastatic sites (respectively) (Figure. 8a, left). Significantly, 10-15\% of metastatic breast cancer patients will develop brain metastases, making breast cancer the second most common source of brain metastasis [11]. A similar distribution of metastasis is seen following relapse (post-treatment), with around $22 \%$ of patients having multiple sites of metastasis (Figure. 8b, right) $[12,13]$.

Further examining metastasis by molecular breast cancer subtypes, distinctive patterns of metastasis sites are observed. Bone metastases remain the most common metastatic site in luminal A, B and Her2+ve breast cancers [14-16].

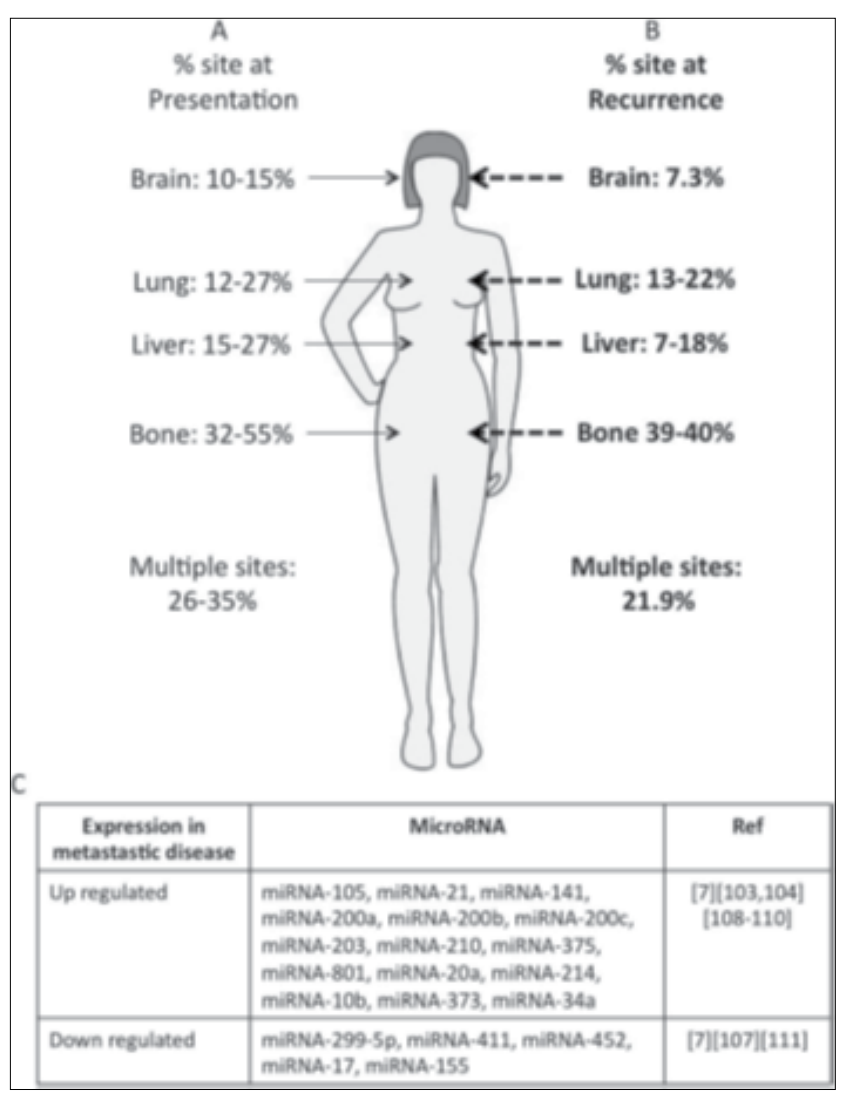

Figure 1: (from Andrew McGuire and col. 2015): A sites of metastatic breast cancer at presentation/diagnosis. B Recurrence sites of metastatic breast cancer. C Summary of published miRNA-associated breast cancer [17].

Here, we present to the cDNA-peptide fusion a more stable anti-tumoral against breast and ovarian cancer. As cDNA target we used primers from her2 gene fusion with peptides from Her2 and human PARP-1 proteins [18].

Her2 gene encodes a member of the human epidermal growth factor (EGF) receptor family of receptor tyrosine kinases. Her2 positive breast cancer represent approximately $20 \%$ of all breast cancer cases and is defined by the overexpression of Her2 oncoprotein with a molecular weight of $185 \mathrm{kDa}$ $[19,20]$. This protein has no ligand binding domain of its own, therefore, cannot bind growth factors. However, it does bind tightly to other ligand-bound EGF receptor family members to form a heterodimer, stabilizing ligand binding and enhancing kinase-mediated activation of downstream signaling pathways, such as those involving mitogen-activated protein kinase and phosphatidylinositol-3 kinase. An amplification and/or overexpression of this gene has been reported in numerous cancers, including breast and ovarian tumors. Alternative splicing results in several additional transcript variants, some encoding different isoforms and others that have not been fully characterized. [provided by RefSeq, Jul 2008]. 
Different miRNAs have been reported to be dysregulated (overexpression or downregulation) in human malignancies including breast, ovarian, colon, lung and other types of carcinoma. These studies have shown that miRNAs such as miR-21, miR-29, miR-155, miR-2010, miR-135, miR-342, miR-634, miR-491 and miR-637 have a diagnostic role in Her2 pathway in positive breast cancer carcinoma [20,21]

Her2 miRNAs are found circulating in the blood, presenting an opportunity to use these circulating disease-related miRNAs as biomarkers [22].

PARP-1 hyperactivation induces rapid depletion of the NAD+ pool. The L-type amino acid transporter 1 (LAT1) known as LAT1-NAD+-SIRT1 signaling is activated in tumor tissues of patients with non-small cell lung cancer (NSCLC). With oxidative challenge induced DNA damage, accumulation of DNA damage in sensing excessive oxidative stress human PARP-1 in stressed cells induce apoptosis pathways [23].

Our analysis identified 16 cloning DNA (cDNA) with theorical fusion stability (FS) values in the range 49.30-62.41 and theoretical Exosome Affinity (EA) (cDNA-peptide and exosome) among 62.60-77.10 range. We proposed a cDNApeptide with theorical fusion value stability $\mathrm{FS}=50.36 \mathrm{Cruz}$ and exosome affinity $\mathrm{EA}=68.02$ Ro. We have named the cDNA-peptide selection as: LCR_2020_B008-55.

Additionally, in Silico, this cDNA-peptide is also manifests partial inhibiting activity on the methylated promoter genes in lung tumors, therefore, this chimera cDNA-peptide may reach a high representative antitumoral activity against lung cancer disease [24].
It has been identified that $70 \%$ of metastatic breast cancer patients developed secondary lung cancer [25]. Lung cancer is the most common cause of cancer deaths worldwide. The two broad histological subtypes of lung cancer are small-cell lung cancer (SCLC), accounting for $15 \%$ of cases, and nonsmall-cell lung cancer (NSCLC), accounting for some $85 \%$ of cases. NSCLC therefore is one of the most common malignant tumors and the leading cause of cancer-related death in all genders, men and women [26].

Lung cancer is the most common cause of cancer deaths worldwide. The two broad histological subtypes of lung cancer are small-cell lung cancer (SCLC), accounting for $15 \%$ of cases, and non-small-cell lung cancer (NSCLC), accounting for some $85 \%$ of cases. NSCLC therefore is one of the most common malignant tumors and the leading cause of cancerrelated death in all genders, men and women [22].

According to anti-tumoral monitoring before and after vaccination using the candidate LCR_2020_B008-55 we proposed exosomes as biomarkers of lung carcinogenesis: after and before vaccination. Due to, the cDNA-peptides, in Silico, manifest with high exosome affinity, our proposal vaccine may reach a high representative activity against breast, ovarian and lung cancer in a metastasis stage, we identified this chimera with a triple antitumoral action [27]

Exosomes are defined as extracellular vesicles with a diameter of 30-100 nm, containing proteins, nucleic acids, lipids, etc., which are secreted by various cells into the microenvironment. Increasing evidences implicate exosomes as important molecular vehicles, potentially also distally, participating in

physiological and pathological processes, such as tumor initiation, progression, and response to therapy in a number of human cancers including NSCLC [24].

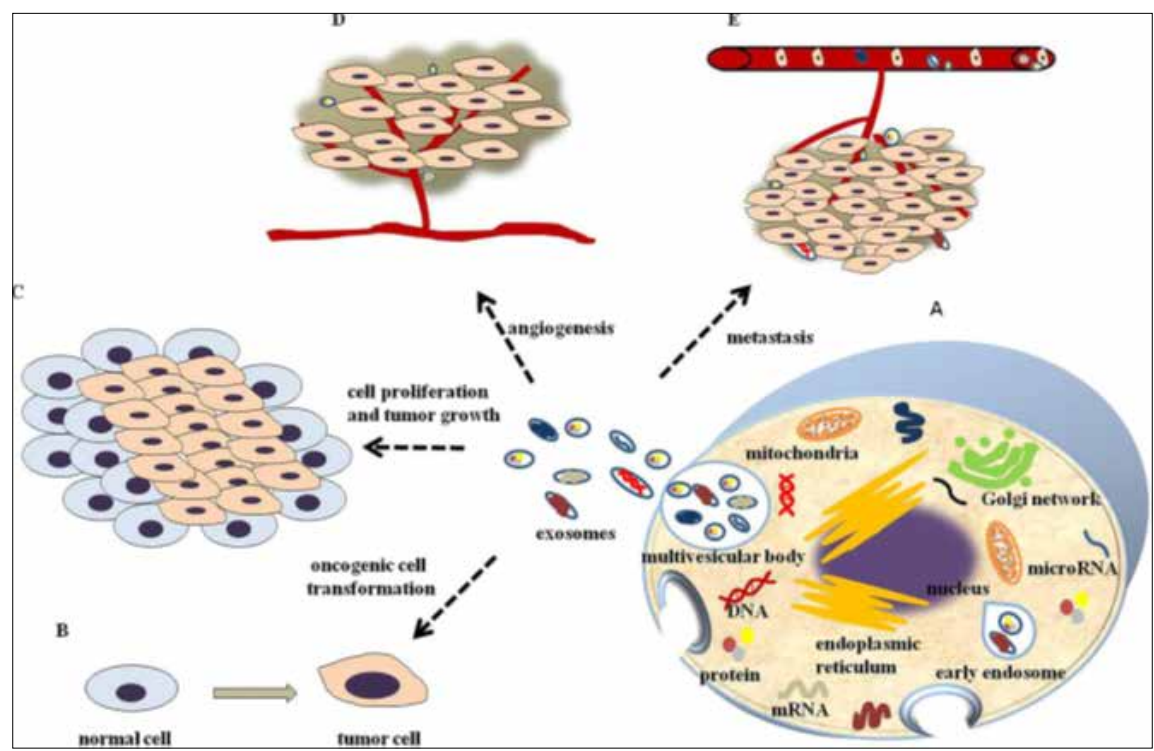

Figure 2: (from S. Liu and col. 2019). The formation of exosomes and their roles in the process of carcinogenesis, progression, invasion and metastasis of NSCLC. A: The process of the formation of exosomes is presented on the cells, and exosomes release to the extracellular environment; B: Exosomes induce normal cells transform into tumor cells; C: Exosomes promote cell proliferation and tumor growth; D: Exosomes stimulate angiogenesis; E: Tumor-derived exosomes promote angiogenesis and 
cancer cell growth, invasion and distant metastasis [24].

Despite progress in the development of drugs that efficiently target cancer cells, treatments for metastatic tumours are often ineffective. The now well-established dependency of cancer cells on their microenvironment suggests that targeting the non-cancer-cell component of the malignancy might form a basis for the development of novel therapeutic approaches. However, the as-yet poorly characterized contribution of host responses during malignancy growth and metastatic progression represents a limitation to exploiting this approach [25]. One aim of this is to better understand potential dormant repositories of outbreaks and potential metastasis of breast cancer disease and its consequences in lung malignancies.

As a vaccine candidate we also propose to integrate research in vaccine testing with 'wild type' genomic phylogenic evolution studies as a part of antitumoral Medical Geology studies utilizing a small part of the LCR 2020 B008-55 vaccine funding. This is highly recommended since this would trace the bio-geochemical consequences of genotoxin genetic susceptibilities (eg arsenic synergy enhanced polymetallic toxicant) variation along the pathological pathway chain from environment [23].

LCR_2020_B008-55:

(5' AAAAAAAA--gecttatggetgectcttagacc--CCCCC-TSPKANKEILDEVDGVDEVAKKKSK)

\section{Materials and Methods}

Homology modelling has evolved into an important procedure in structural biology, significantly contributing to narrowing the gap between known protein sequences from a tumoral cell and designed human ADP-ribosylating enzyme PARP-1 peptides in Silico structures [26].
Antitumoral peptides were designed to be used in human PARP-1 as a protein inhibitor. The inhibition is due to protein on protein interactions. A cleavage site has been adjusted (DEVD) in the peptide to induce the caspases 3 and 7 cascade action, and thereby apoptosis in infected cells. On the other hand, in cells not affected in cycle division the apoptosis is not induced, and the synthesis of the miRNA will allow an antigen involved in the production of antibodies against the overexpression of Her2 gene [17].

Both of the cDNA 3' and peptide N-terminus will be modified for click chemistry conjugation.

\section{Gene targets:}

The Her2 cDNA primers are named LCR (Luis CRUZ RODRIGUEZ) and their targets are show following:

a) LCR-1 (5'gccagccetgtgacgtccatcatt3'),

b) LCR-2 (5' aatcaagcgaaggcggcagaagat 3 '),

c) LCR-3 (5'cggaggctgctgcaggagacggag3'),

d) LCR-4 (5'cagtctgagggectccetgttggctt3'),

e) LCR-5 (5'tctacagcccagcctccttcactg $\left.3^{\prime}\right)$,

f) LCR-6 (5' caccccctcgecccagctggtgg $\left.3^{\prime}\right)$,

g) LCR-7 (5'tgaggaaggtgaaggtgcttggatcc 3'),

h) LCR-8 (5'ctttggcactgtctacaaggt3'),

i) LCR-11 (5'gggccaaagttcctgggtgggcggtcc 3'),

j) LCR-23 (5'aggatacagcgggtgtggccaagcgtt3'),

k) LCR-44 (5' atcctcttctctctgecccaggg 3 '),

1) LCR-51 (5' cccacaccttctcagggtgcactctt 3 '),

m) LCR-55 (5' 'gccttatggetgectcttagacc 3'),

n) LCR-59 (5'acgagacagagtaccatgccgatggggg3'),

o) LCR-63 (5' 'gaggagagcagggatagaattaatgg3'),

p) LCR-74 (5'gggggaacggetgecccagceccec3'),

All cloning primers (cDNA) were validated for their stability after peptide fusion. The following statistical analysis [18].

\begin{tabular}{|l|l|l|l|l|l|l|l|}
\hline cDNA & A & T & C & G & SUMA & PRIMER & PEPTIDE \\
\hline LCR-1 & 14 & 6 & 9 & 5 & 34 & $\begin{array}{l}\text { AAAAAAAAAA-- } \\
\text { gccagcctgtgacgtccatcatt }\end{array}$ & $\begin{array}{l}\text { CCCCC-- } \\
\text { TSPKANKEILDE } \\
\text { VDGVDEVAKKKSK }\end{array}$ \\
\hline LCR-2 & 18 & 2 & 4 & 8 & 32 & $\begin{array}{l}\text { AAAAAAAA-- } \\
\text { aatcaagcgaaggcggcagaagat }\end{array}$ & $\begin{array}{l}\text { CCCCC-- } \\
\text { TSPKANKEILDEVD } \\
\text { GVDEVAKKKSK }\end{array}$ \\
\hline LCR-3 & 13 & 2 & 5 & 12 & 32 & $\begin{array}{l}\text { AAAAAAAA-- } \\
\text { cggaggctgctgcaggagacggag }\end{array}$ & $\begin{array}{l}\text { CCCCC-- } \\
\text { TSPKANKEILDEVD } \\
\text { GVDEVAKKKSK }\end{array}$ \\
\hline LCR-4 & 10 & 8 & 8 & 8 & 34 & $\begin{array}{l}\text { AAAAAAAA-- } \\
\text { cagtctgagggcctcctgttggctt }\end{array}$ & $\begin{array}{l}\text { CCCCC-- } \\
\text { TSPKANKEILDEVD } \\
\text { GVDEVAKKKSK }\end{array}$ \\
\hline LCR-5 & 12 & 6 & 11 & 3 & 32 & $\begin{array}{l}\text { AAAAAAAA-- } \\
\text { tctacagccagctccttcactg }\end{array}$ & $\begin{array}{l}\text { CCCCC-- } \\
\text { TSPKANKEILDEVD } \\
\text { GVDEVAKKKSK }\end{array}$ \\
\hline
\end{tabular}




\begin{tabular}{|c|c|c|c|c|c|c|c|}
\hline LCR-6 & 10 & 3 & 13 & 6 & 32 & $\begin{array}{l}\text { AAAAAAAA-- } \\
\text { cacceccctcgeccagctggtgg }\end{array}$ & $\begin{array}{l}\text { CCCCC-- } \\
\text { TSPKANKEILDEVD } \\
\text { GVDEVAKKKSK }\end{array}$ \\
\hline LCR-7 & 14 & 6 & 3 & 11 & 34 & $\begin{array}{l}\text { AAAAAAAA-- } \\
\text { tgaggaaggtgaaggtgcttggatcc }\end{array}$ & $\begin{array}{l}\text { CCCCC-- } \\
\text { TSPKANKEILDEVD } \\
\text { GVDEVAKKKSK }\end{array}$ \\
\hline LCR-8 & 12 & 8 & 5 & 5 & 30 & $\begin{array}{l}\text { AAAAAAAA-- } \\
\text { cttttggcactgtctacaaggt }\end{array}$ & $\begin{array}{l}\text { CCCCC-- } \\
\text { TSPKANKEILDEVD } \\
\text { GVDEVAKKKSK }\end{array}$ \\
\hline LCR-11 & 11 & 5 & 7 & 12 & 35 & $\begin{array}{l}\text { AAAAAAAA-- } \\
\text { gggccaaagttcctgggtgggcggtcc }\end{array}$ & $\begin{array}{l}\text { CCCCC-- } \\
\text { TSPKANKEILDEVD } \\
\text { GVDEVAKKKSK }\end{array}$ \\
\hline LCR-23 & 14 & 5 & 5 & 11 & 35 & $\begin{array}{l}\text { AAAAAAAA-- } \\
\text { aggatacagcgggtgtggccaagcgtt }\end{array}$ & $\begin{array}{l}\text { CCCCC-- } \\
\text { TSPKANKEILDEVD } \\
\text { GVDEVAKKKSK }\end{array}$ \\
\hline LCR-44 & 10 & 7 & 10 & 4 & 31 & $\begin{array}{l}\text { AAAAAAAA-- } \\
\text { atcctcttctctctgccccaggg }\end{array}$ & $\begin{array}{l}\text { CCCCC-- } \\
\text { TSPKANKEILDEVD } \\
\text { GVDEVAKKKSK }\end{array}$ \\
\hline LCR-51 & 12 & 7 & 10 & 5 & 34 & $\begin{array}{l}\text { AAAAAAAA-- } \\
\text { cccacaccttctcagggtgcactctt }\end{array}$ & $\begin{array}{l}\text { CCCCC-- } \\
\text { TSPKANKEILDEVD } \\
\text { GVDEVAKKKSK }\end{array}$ \\
\hline LCR-55 & 11 & 7 & 7 & 5 & 31 & $\begin{array}{l}\text { AAAAAAAA-- } \\
\text { gccttatggctgcctcttagacc }\end{array}$ & $\begin{array}{l}\text { CCCCC-- } \\
\text { TSPKANKEILDEVD } \\
\text { GVDEVAKKKSK }\end{array}$ \\
\hline LCR-59 & 16 & 3 & 6 & 11 & 36 & $\begin{array}{l}\text { AAAAAAAA-- } \\
\text { acgagacagagtaccatgccga } \\
\text { tggggg }\end{array}$ & $\begin{array}{l}\text { CCCCC-- } \\
\text { TSPKANKEILDEVD } \\
\text { GVDEVAKKKSK }\end{array}$ \\
\hline LCR-63 & 18 & 4 & 1 & 11 & 34 & $\begin{array}{l}\text { AAAAAAAA-- } \\
\text { gaggagagcagggatagaatt aatgg }\end{array}$ & $\begin{array}{l}\text { CCCCC-- } \\
\text { TSPKANKEILDEVD } \\
\text { GVDEVAKKKSK }\end{array}$ \\
\hline LCR-74 & 11 & 1 & 12 & 9 & 33 & $\begin{array}{l}\text { AAAAAAAA-- } \\
\text { gggggaacggctgccccagcccccc }\end{array}$ & $\begin{array}{l}\text { CCCCC-- } \\
\text { TSPKANKEILDEVD } \\
\text { GVDEVAKKKSK }\end{array}$ \\
\hline
\end{tabular}

Table 1 shows the 16 cDNA primers used as fusion with the selected peptide for the vaccine against the breast and ovarian cancer diseases. On the table the number of nitrogenated bases and the size of the primer can be seen in the table. The Polyadenylation (number of adenines adjusted at the 5 ' end of the primer and the number of Cys adjusted to the peptide utilized as a spacing arm between the cDNA and the peptide.)

This peptide begins with the amino acid cysteine (C) to facilitate fusion with the 3 ' of cDNA.

The peptide utilized was the following:

- Full peptide sequencing (30 amino acids)

CCCCC--TSPKANKEILDEVDGVDEVAKKKSK 


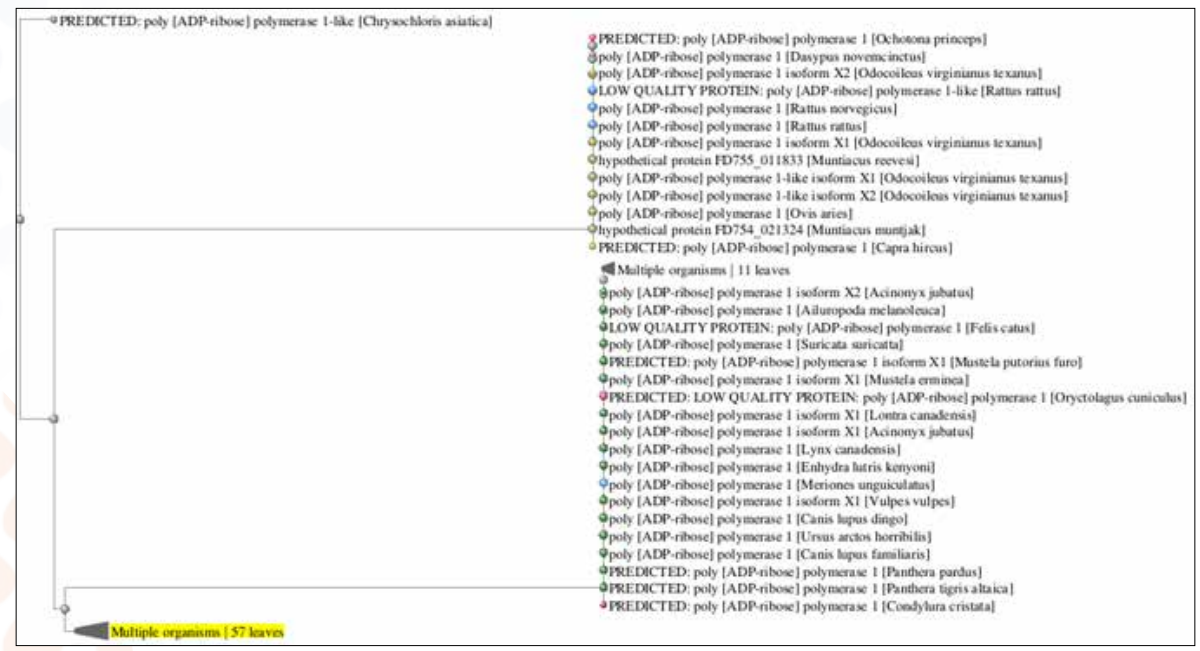

Figure 3 indicates the blast of peptide Her2-Parp1 fusion.

After cleavage of caspase $3 / 7$

I) SARS-CoV-2 (19 amino acids)

\section{CCCCC-TSPKANKEILDEVDGVDEVAKKKSK}

The mathematical formula utilized to estimate the Fusion Stability (FS) among the cDNA and selected peptide is represented as follows:

Let $\mathbf{B}=\mathbf{T}$ if DNA or $\mathbf{B}=\mathbf{U}$ if $\mathrm{RNA}$

$\mathrm{FS}=\mathrm{abcd}$, where:

$$
\begin{aligned}
& a=\frac{S_{\text {Poly } A}}{S_{\text {Poly Cys }}}, \quad b=\frac{M W_{\text {miRNA }}}{M W_{\text {Peptide }}}, \\
& c=\frac{S_{\text {Peptide }}}{S_{\text {miRNA }}}, \quad d=\frac{[2(A+B)+3(C+G)]}{X\left(p I_{1}, p I_{2}, \ldots, p I_{n}\right)},
\end{aligned}
$$

$S_{\text {Poly A }}$

$$
\text { : Poly A size }
$$

$S_{\text {PolyCys }}$

$$
\text { : Poly Cys size }
$$

$$
\begin{array}{ll}
M_{\text {miRNA }} & : \text { miRNA Molecular Weight } \\
M W_{\text {Peptide }} & : \text { Peptide Molecular Weight } \\
S_{\text {Peptide }} & : \text { Peptide size [aa] } \\
S_{\text {miRNA }} & : \text { miRNA Size }
\end{array}
$$

\section{pI : point Isoelectric}

n : peptide size

This formula developed by Prof. Dr. Luis CRUZ-RODRIGUEZ and named as Fusion Stability CRUZ-RODRIGUEZ (FS) and values units in Cruz [18].

The mathematical formula utilized to estimate the Exosome Affinity (EA) between cDNA-peptide and Exosome is expressed as:

$$
E A=F S\left[\left(\frac{M W_{\text {pepticie }}}{M W_{\text {primer }}}\right)+\left(\frac{S_{\text {peptide }}}{S_{\text {primer }}}\right)\right]
$$

Where:

EA : Exosome Affinity

FS : Fusion Stability

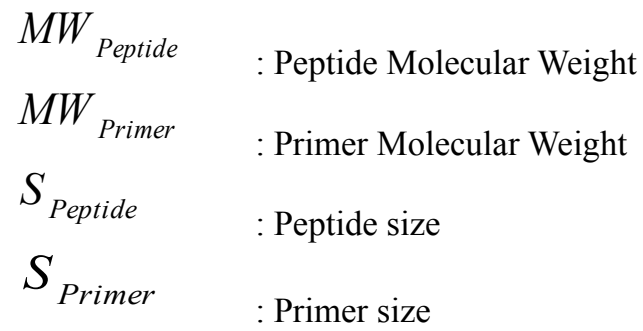

This formula is developed by Prof. Dr. Luis CRUZRODRIGUEZ and named as Exosome Affinity CRUZRODRIGUEZ (EA) and values units in Ro. [20].

\section{Results and Discussion}

\section{Bioinformatics identification of cDNAs}

Prior to our analysis, readings containing poly-N, with 5' Cyspeptide fusion with a 3' insert tag, containing poly-A (add 8 nucleotides of adenine to all primers except primer LCR-1 to which 10 nucleotides of adenine were added). The small cDNA was clustered with a peptide with caspase site $3 / 7$, and the percentage of differential of Fusion Stability (FS) cDNApeptide was calculated.

a) LCR_2020_B008-1(5'AAAAAAAAAAgccagcctgtgacgtccatcatt--CCCCC-TSPKANKEILDEVDGVDEVAKKKSK ), b) LCR 2020 B008-2 (5'AAAAAAAAaatcaagcgaaggcggcagaagat--CCCCC-TSPKANKEILDEVDGVDEVAKKKSK ), 
c) LCR_2020_B008-3 (5'AAAAAAAA-cggaggctgctgcaggagacggag--CCCCC-TSPKANKEILDEVDGVDEVAKKKSK),

d) LCR_2020_B008-4 (5'AAAAAAAA-cagtctgagggectccetgttggctt--CCCCC--

TSPKANKEILDEVDGVDEVAKKKSK),

e) LCR_2020_B008-5 (5'AAAAAAAA-tctacagccagcetcettcactg--CCCCC--

TSPKANKEILDEVDGVDEVAKKKSK),

f) LCR_2020_B008-6 (5'AAAAAAAA-caccccctcgeccagctggtgg--CCCCC--

TSPKANKEILDEVDGVDEVAKKKSK),

g) LCR_2020_B008-7 (5'AAAAAAAA-tgaggaaggtgaaggtgcttggatcc--CCCCC--

TSPKANKEILDEVDGVDEVAKKKSK),

h) LCR_2020_B008-8 (5'AAAAAAAA-ctttggcactgtctacaaggt--CCCCC--

TSPKANKEILDEVDGVDEVAKKKSK),

i) LCR_2020_B008-11 (5'AAAAAAAA-gggccaaagttcetgggtgggeggtcc-CCCCC--

TSPKANKEILDEVDGVDEVAKKKSK), j) LCR_2020_B008-23 (5'AAAAAAAA-aggatacagcgggtgtggccaagcgtt-CCCCC-TSPKANKEILDEVDGVDEVAKKKSK),

k) LCR 2020_B008-44 (5'AAAAAAAA-atcctcttctctctgeccaggg--CCCCC--

TSPKANKEILDEVDGVDEVAKKKSK),

1) LCR_2020_B008-51 (5'AAAAAAAA-cccacaccttctcagggtgcactctt--CCCCC--

TSPKANKEILDEVDGVDEVAKKKSK),

m) LCR_2020_B008-55 (5'AAAAAAAA-gccttatggetgectcttagacc--CCCCC--

TSPKANKEILDEVDGVDEVAKKKSK),

n) LCR_2020_B008-59 (5'AAAAAAAAacgagacagagtaccatgccgatggggg-CCCCC-

TSPKANKEILDEVDGVDEVAKKKSK),

o) LCR_2020_B008-63 (5'AAAAAAAA-gaggagagcagggatagaattaatgg--CCCCC--

TSPKANKEILDEVDGVDEVAKKKSK),

p) LCR_2020_B008-74 (5'AAAAAAAA-gggggaacggetgeccagecccc--CCCCC--

TSPKANKEILDEVDGVDEVAKKKSK),

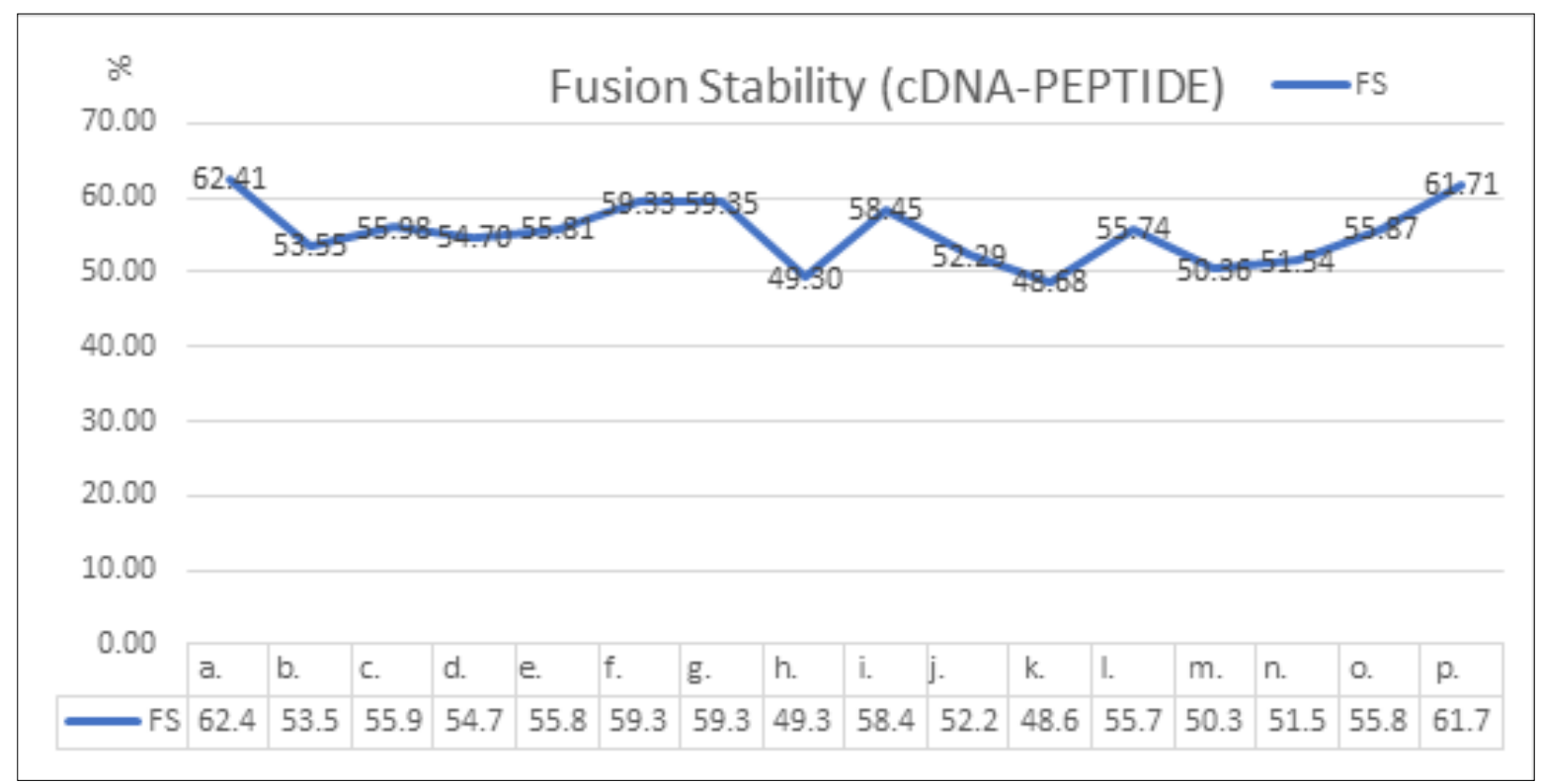

Figure 4 (a, b, c, d, e, f, g, h, I, j, k, l, m, n. o, p: are sixteen cDNA-peptide fusion stability (FS). The cDNA primer for the proposed vaccine against the breast and ovarian cancer disease [18]. 


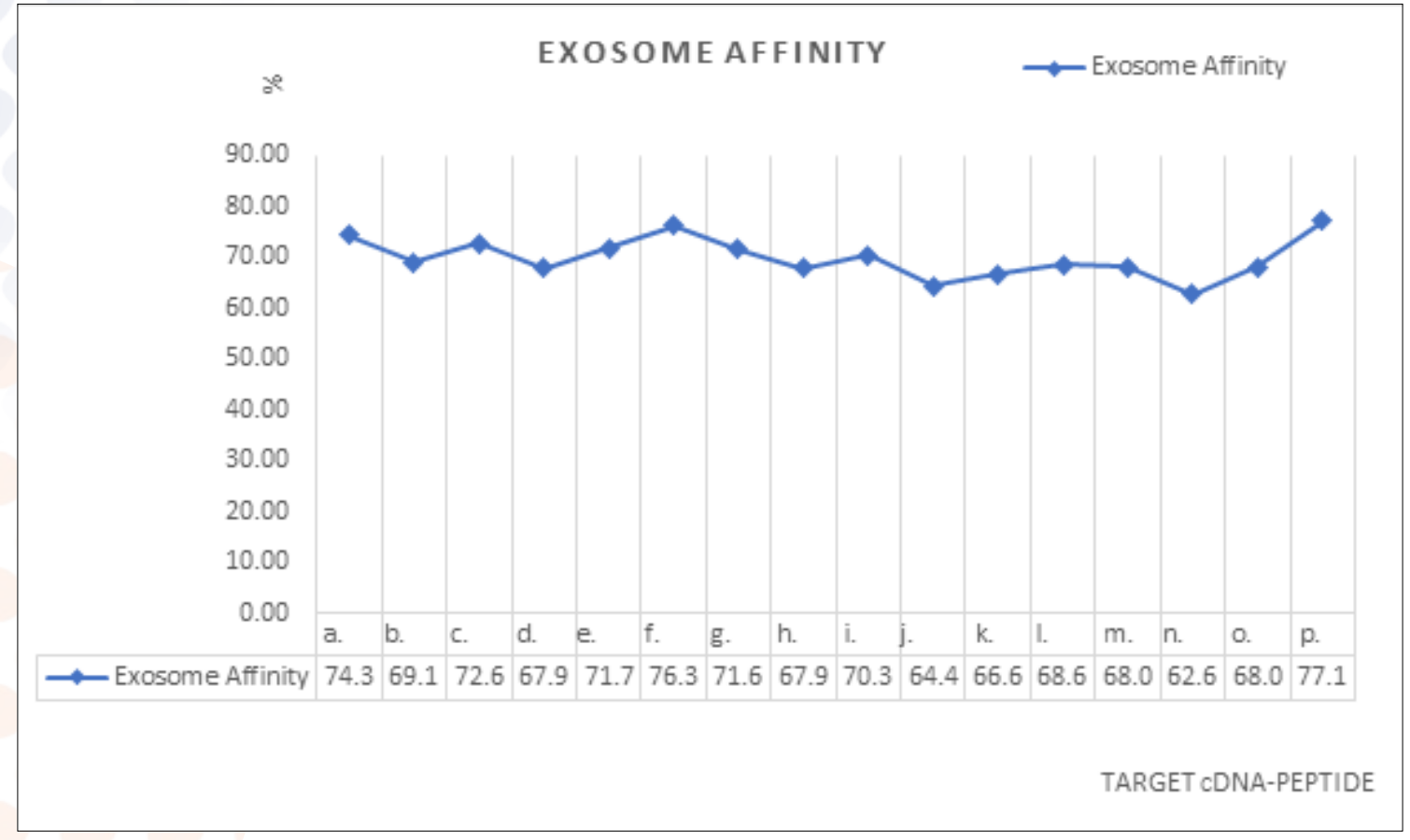

Figure 5 (a, b, c, d, e, f, g, h, I, j, k, l, m, n. o, p: are sixteen cDNA-peptide exosome affinity (EA). The cDNA primer for the proposed vaccine against the breast and ovarian cancer disease [24].

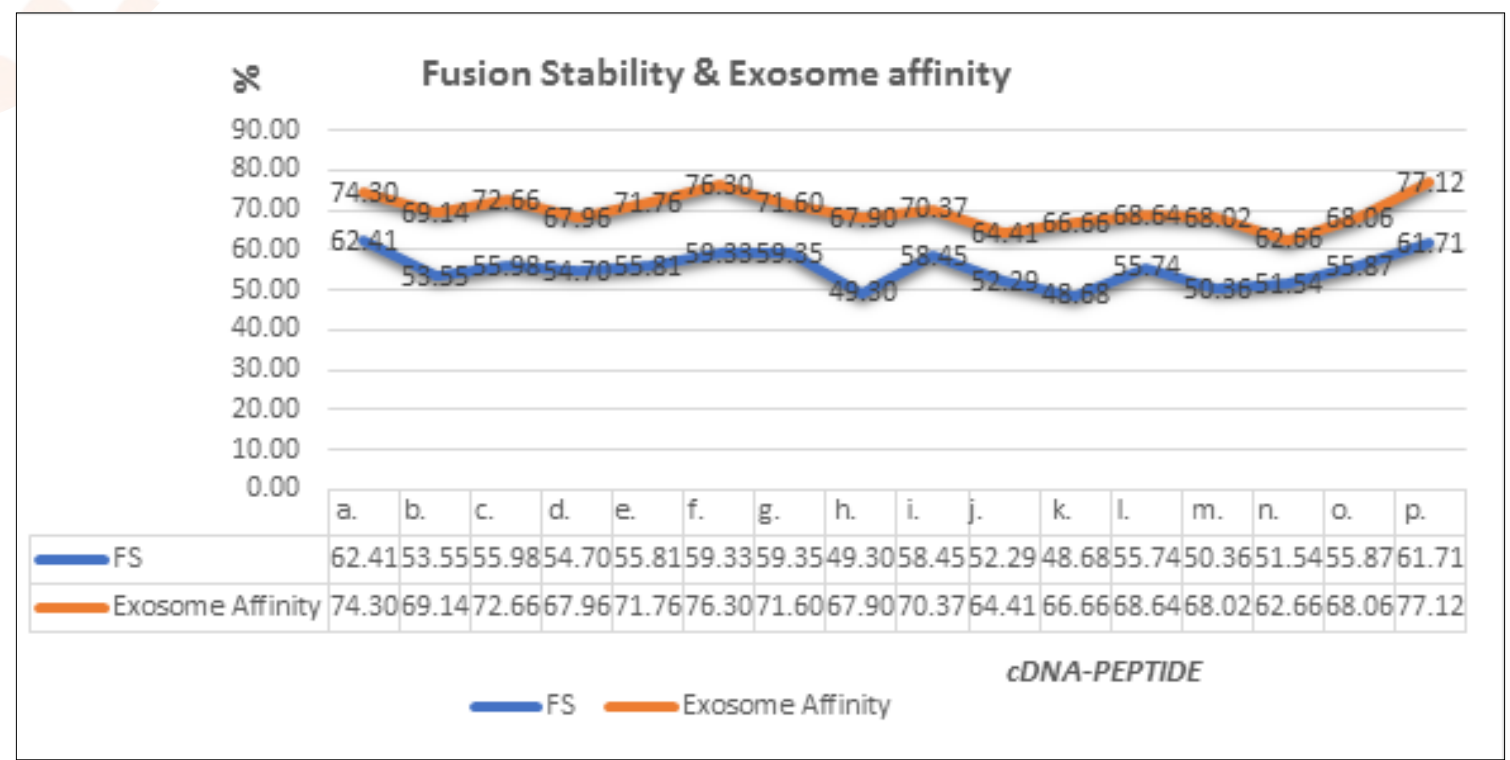

Figure 6 indicates a comparative among the fusion stability (FS) and exosome affinity (EA) for each cDNA and peptide fusion a, b, c, d, e, f, g, h, i, j, k, l, m, n, o, p [18,24].

Candidate selected (cDNA-peptide)

LCR_2020_B008-55 (5’AAAAAAAA--gccttatggctgcctcttagacc--CCCCC--TSPKANKEILDEVDGVDEVAKKKSK)

$\mathrm{FS}=50.36 \mathrm{Cruz}$

$\mathrm{EA}=68.02 \mathrm{Ro}$

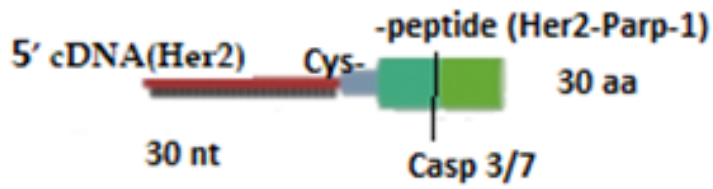

Figure 7 indicates fusion stability (FS) between primers of cDNA and peptide (spacing arm (Poly Cys) and fused molecules Her2 and PARP-1) [18]. 


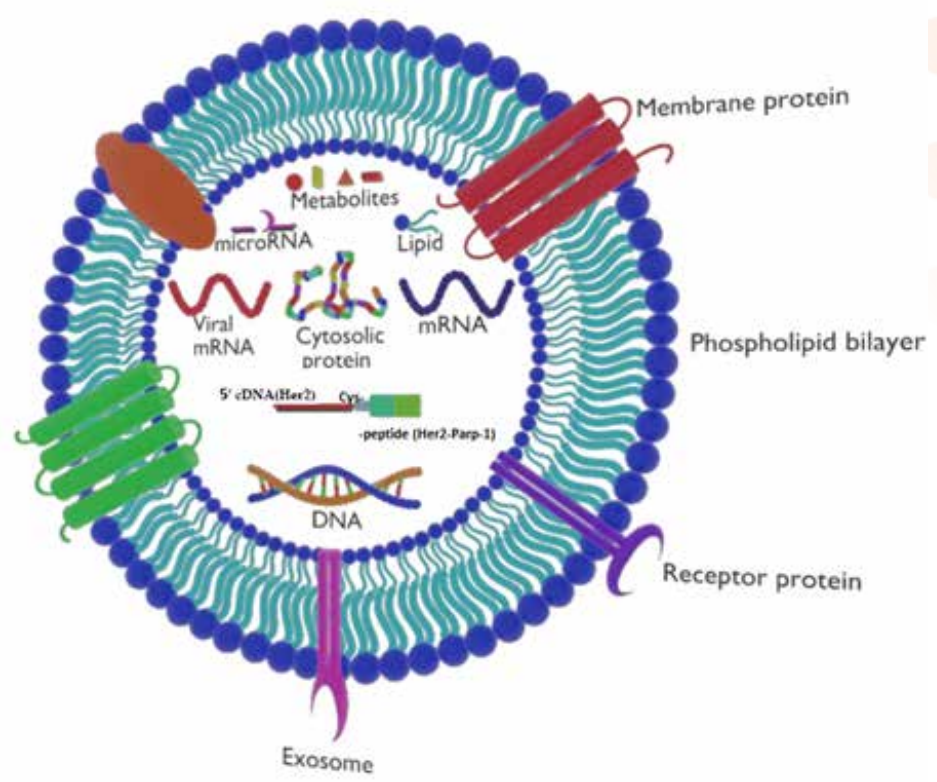

Figure 8 indicates the structure and content of exosome. Exosomes contain various types of proteins, nucleic acids, lipids and metabolites [24].

By using ProMod3 and introducing a new local model quality estimation method, known as QMEANDisCo. SWISS-MODEL (https://swissmodel.expasy.org). We present here an update to the SWISS-MODEL server, with candidate LCR_2020_B008-55 of antitumoral breast and ovarian cancer.

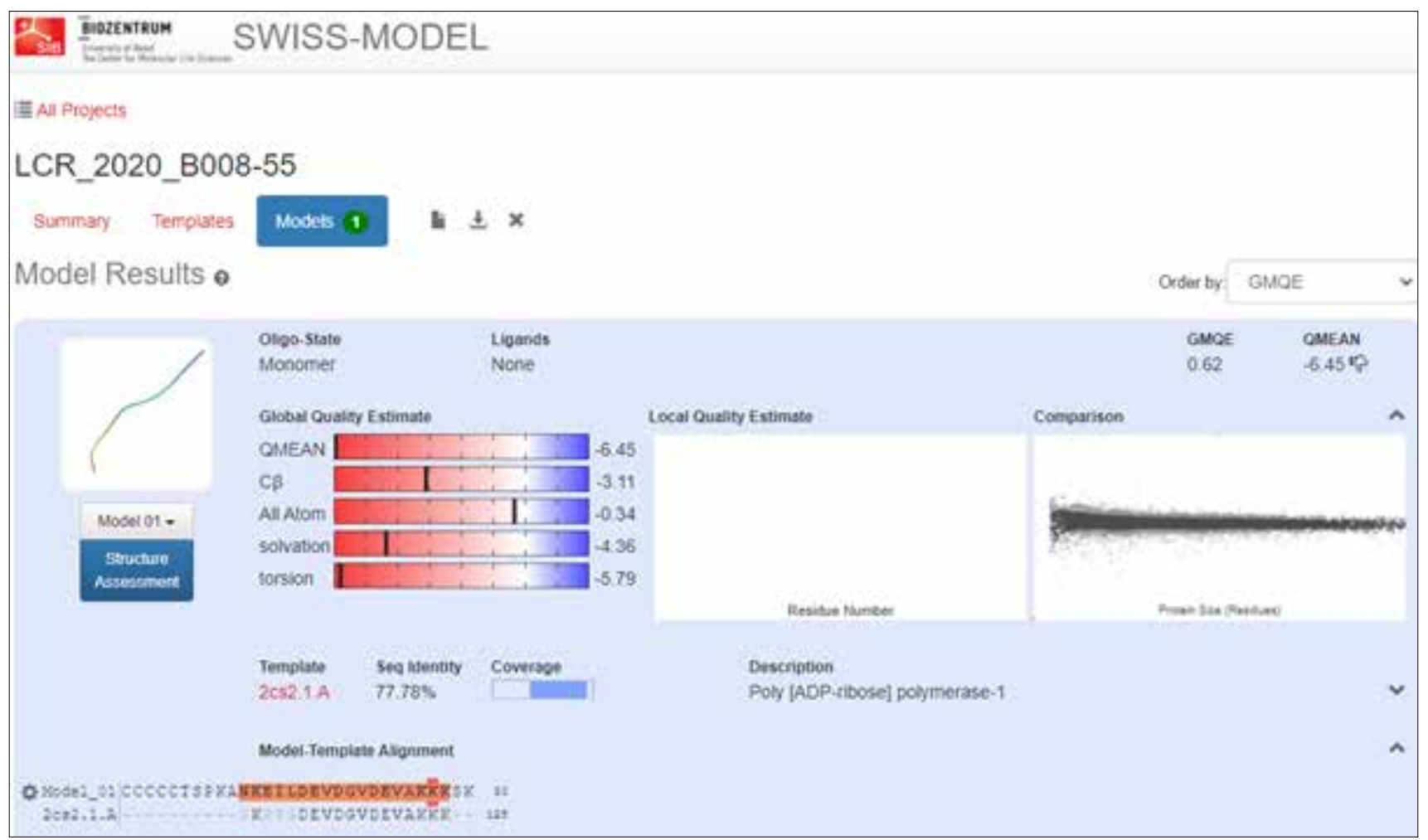

Figure 9 indicates: SWISS-MODEL of peptide CCCCCTSPKANKEILDEVDGVDEVAKKKSK (30 aa). Description as PARP-1.

https://swissmodel.expasy.org/interactive/5KtHC7/models/ LCR_2020_B008-55 (5'AAAAAAAA-

From the selected candidate: cDNA poly-A (31 nt)-peptide (30 -gccttatggctgcctcttagacc--CCCCC--

aa)

TSPKANKEILDEVDGVDEVAKKKSK)

We present an update to: miRNA, full peptide sequencing and 
the two peptides after caspase $3 / 7$ cleavage.

cDNA poly-A (31 nt)-peptide (23 aa) + peptide (11 aa)

5'AAAAAAAA--gcttatggetgectcttagacc--CCCCCTSPKANKEILDEVDGVDEVAKKKSK

The mapped small cDNAs reading were examined for the presence of the known cDNAs using the corresponding miRNA at miRBase20.0 (http://www.mirbase.org ). Based on this analysis 16 vaccine candidates were identified. The Differential cDNA-peptide fusion stability curve was calculated and Alignment of Query to mature miRNAs (see figure following).

cDNA LCR-55:

5'AAAAAAAAGCCTTATGGCTGCCTCTTAGACC

miRNA LCR-55:

5'AAAAAAAAGCCUUAUGGCUGCCUCUUAGACC

\begin{tabular}{|c|c|c|c|}
\hline \multicolumn{4}{|c|}{ Alignment of Query to mature miRNAs } \\
\hline Query: 11-26 & gga-miR-1567: 6-21 & & score: 62 \\
\hline Userseq & 11 evuauggeugecueuu & 26 & \\
\hline$g g s-m i R-1567$ & $6 \int_{\text {cucouggeugecuguu }}$ & 21 & \\
\hline Query: 5-20 & $p x y-m i R-8514-3 p: 2-17$ & & score: 62 \\
\hline Userseq & 5 sasoggceuvauggcug & 20 & \\
\hline$p x y-n i R-8514-3 p$ & 17 osasgecguaucgeug & 2 & \\
\hline Query: 5-20 & dvi-miR-986-5R: 6-21 & & score: 62 \\
\hline UserSeq & 5 asasagceuuauggcug & 20 & \\
\hline dvi-miR-986-5p & 6 osuagcauvouggeug & 21 & \\
\hline
\end{tabular}

Figure 10 indicates: Alignment of Query to mature miRNA LCR-55

\section{Conclusion and Perspectives}

Our analysis in Silico identified a stable fusion cDNA-peptide from 16 vaccine candidates aimed to treat breast and ovarian metastasis.

The vaccine candidate with the 50 percent of value $(\mathrm{FS}=50 \%)$ was named: LCR_2020_B008-55:

It presents a cleavage site for enzymes caspase- 3 and caspase-7, both activated universally during apoptosis. Inoculation is expected to be orally with appropriate doses.

With regards to the antitumoral, the candidate LCR_2020 B008-55, manifests in Silico, a partial inhibiting activity on lung cancer pathways, which means that readjustments in this chimera cDNA-peptide may reach a high representative antitumoral activity against the lung malignancy.

All in all, our research study and our proposed vaccine contributes greatly to the cancer research where we may reach a higher representative activity against breast, ovarian and lung cancer in a metastasis stage due to the fact that cDNA-peptides, in Silico, highly manifest affinity with exosomes.

Due to cDNA-peptides in Silico having high affinity with exosomes, monitored before and after vaccination aims to achieve representative activity against breast, ovarian and lung cancer in metastasis stage, the chimera proposed having triple antitumoral action.

Selection of $50 \%$ fusion Stability is pertinent to quantitatively match the molecules fusioned cDNA-PEPTIDE as cDNA and PEPTIDE molecules, both inducing PARP-1 depletion and thence apoptosis, 'independent' of pathway. Moreover, a 50\% of Fusion Stability ensures high quality chimera PEPTIDE within exosomes, likely exceeding $60 \%$, to project transfer efficacy toward other cells of metastasis, so enabling lung cell predominance and thereby cancer disease prevention.

'Wild type' genomic phylogenic evolution studies as a part of antitumoral Medical Geology studies during LCR_2020 B008-55 vaccine research is proposing to trace closely the biogeochemical consequences of genotoxin (eg arsenic synergy enhanced polymetallic) genetic susceptibility variation along the pathological pathway chain from environment. By linking our vaccine monitoring and biotechnology methodology, deeper epidemiological cancer insights will emerge from geological-physiographic and cultural anthropogenic environmental factors in gentoxicity and its amelioration, further aiding prevention.

\section{References}

1. Hannah K Weir, Trevor D Thompson, Ashwini Soman, Bjorn Moller, Steven Leadbetter (2015) "The past, present, and future of cancer incidence in the United States: 1975 through 2020": Cancer 121(11): 1827-1837.

2. Juan Carlos Martín-Sánchez, Nuno Lunet, Adrian Gonzalez-Marrion, Cristina Lidon-Moyano, Nuria Matilla-Santander, Ramon Cleries, Matteo Malvezzi, Eva Negri, Samantha Morais, Ana Rute Costa, Ana Ferro, Luisa Lopes-Conceicao, Carlo La Vecchia, and Jose M. Martínez-Sánchez (2018) "Projections in Breast and Lung Cancer Mortality among Women: A Bayesian Analysis of 52 Countries Worldwide": Cancer Res; 78(15) August 1, 2018.

3. Siegel, R., Naishadham, D., Jemal, A (2013) Cancer statistics, 2013. CA: A Cancer Journal for Clinicians 63: 11.

4. Sepideh Tajik, Parisa Ziarati, Cruz-Rodriguez L. (2020) "Coffee Waste as Novel Bio-adsorbent: Detoxification of Nickel from Contaminated Soil and Coriandrum Sativum “. 2020. Journal of Bioscience \& Biomedical Engineering 1(3): 1-11.

5. KAMYAB-MOGHADAS B., ZIARATI P., CRUZRODRIGUEZ L (2020) "BREAST CANCER DISEASE AND ARSENIC: GEOLOGY BEHAVIOR AS KEY "2020 Gynecology and Women's Health Care 2(3): 1-8.

6. ZIARATI P., HOCHWIMMER B., LAMBERT BROWN 
D., MORADI M. and CRUZ-RODRIGUEZ L (2020) “ Breast Cancer disease and Heavy Metal: Cadmium as Key in "Medical Geology": G Women's Health Car 2(2): 1-13.

7. Gupta, G. P., Massague, J. (2006) "Cancer metastasis: building a framework" Cell 127: 79.

8. Muller, A., et al. (2001) "Involvement of chemokine receptors in breast cancer metastasis". Nature 410: 50.

9. Ernst, M. F., et al. (2007) "Trends in the prognosis of patients with primary metastatic breast cancer diagnosed between 1975 and 2002". Breast 16: 344.

10. Ren, Z., Li, Y., Hameed, O., Siegal, G. P., Wei, S. (2014) "Prognostic factors in patients with metastatic breast cancer at the time of diagnosis". Pathology Research and Practice 210: 301.

11. Morris, P. G., et al. (2010) "Integrated positron emission tomography/computed tomography may render bone scintigraphy unnecessary to investigate suspected metastatic breast cancer". Journal of Clinical Oncology 28: 3154 .

12. Barnholtz-Sloan, J. S., et al. (2004) "Incidence proportions of brain metastases in patients diagnosed (1973 to 2001) in the Metropolitan Detroit Cancer Surveillance System". Journal of Clinical Oncology 22: 2865.

13. Sihto, H., et al. (2011) "Breast cancer biological subtypes and protein expression predict for the preferential distant metastasis sites: a nationwide cohort study". Breast Cancer Research 13: R87.

14. Berman, A. T., Thukral, A. D., Hwang, W. T., Solin, L. J., Vapiwala, N. (2013) "Incidence and patterns of distant metastases for patients with early-stage breast cancer after breast conservation treatment". Clinical Breast Cancer 13: 88.

15. Kennecke, H., et al. (2010). "Metastatic behavior of breast cancer subtypes". Journal of Clinical Oncology 28: 3271.

16. J.M. Matro et al. (2014) "Inflammatory breast cancer management in the national comprehensive cancer network: the disease, recurrence pattern, and outcome". Clinical Breast Cancer 15(1): 1-7.

17. Andrew McGuire, James A. L. Brown, \& Michael J. Kerin (2015) "Metastatic breast cancer: the potential of miRNA for diagnosis and treatment monitoring": Cancer Metastasis Rev 34: 145-155.

18. CRUZ-RODRIGUEZ L, CRUZ-RODRIGUEZ LD, SANCHEZ BATISTA L, HOCHWIMMER B (2020) " Calculation of Fusion Stability of [DNA or RNA] Peptide (FS) Algorithm "Cruz-Rodriguez"J B \& Bio Engine; 2020, vol 2, issue 1.

19. Loibl, S.; Gianni, L. HER2-positive breast cancer. Lancet 2017, 389, 2415-2429

20. Asif, H.; Sultana, S.; Ahmed, S.; Akhtar, N.; Tariq, M. HER-2 positive breast cancer, A mini review. Asian Pac.J. Cancer Prev. 2016, 17, 1609-1615

21. Sareyeldin, R. M., Gupta, I., Al-Hashimi, I., Al-Thawadi, H. A., Al Farsi, H. F., Vranic, S., \& Al Moustafa, A. E. (2019). Gene expression and miRNAs profiling: function and regulation in human epidermal growth factor receptor 2 (HER2)-positive breast cancer. Cancers, 11(5), 646

22. Wu, H., Wang, Q., Zhong, H., Li, L., Zhang, Q., Huang,
Q., \& Yu, Z. (2019). Differentially expressed microRNAs in exosomes of patients with breast cancer revealed by next generation sequencing. Oncology reports, 43(1), 240250).

23. Huiying Liu, Rong Xing, Xuefang Cheng, Qingran Li, Fang Liu, Hui Ye, Min Zhao, Hong Wang, Guangji Wang, Haiping Hao (2016) "De-novo NAD+ synthesis regulates SIRT1-FOXO1 apoptotic pathway in response to NQO1 substrates in lung cancer cells": Oncotarget. 7(38): 6250362519.

24. CRUZ-RODRIGUEZ L, SANCHEZ BATISTA L, HOCHWIMMER B, BIN ZHAO and ZIARATI P. " (2020) The mathematical formula to estimate the Exosome Affinity between miRNA-peptide and Exosome: ALGORITHM "CRUZRODRIGUEZ (EA), Journal of Bioscience \& Biomedical Engineering, Volume 1, Issue 2.

25. Wong, G. L., Abu Jalboush, S., \& Lo, H. W. (2020). Exosomal MicroRNAs and Organotropism in Breast Cancer Metastasis. Cancers, 12(7), 1827

26. Elizabeth K Duperret, Shujing Liu, Megan Paik, Aspen Trautz, Regina Stoltz , Xiaoming Liu, Kan Ze, Alfredo Perales-Puchalt, Charles Reed, Jian Yan, Xiaowei Xu, David B Weiner (2018) “A Designer Cross-reactive DNA Immunotherapeutic Vaccine that Targets Multiple MAGE-A Family Members Simultaneously for Cancer Therapy": Clin Cancer Res 24(23): 6015-6027.

27. Matthew G Oser, Matthew J Niederst, Lecia V Sequist, Jeffrey A Engelman. (2015) "Transformation from nonsmall-cell lung cancer to small-cell lung cancer: molecular drivers and cells of origin": Lancet Oncol 16(4): e165-172.

28. CRUZ-RODRIGUEZ L., DILSIZ N., ZIARATI P., LAMBERT BROWN D., HOCHWIMMER B., ZAYAS TAMAYO AM., SANCHEZ BATISTA L., MORADI M (2020) "A miRNA-PEPTIDE FUSION AS A VACCINE CANDIDATE AGAINST THE NOVEL CORONAVIRUS (COVID-19). EXOSOMES AS POTENTIAL BIOMARKERS OF SARS-COV-2 IN LUNG: AFTER AND BEFORE VACCINATION LCR_2020_B008-13" International Journal of Infectious Diseases and Research, 2020.

29. Sile Liu, Yuting Zhan, Jiadi Luo, Juan Feng, Junmi Lu, Hongmei Zheng, Qiuyuan Wen, Songqing Fan (2019) "Roles of exosomes in the carcinogenesis and clinical therapy of non-small cell lung cancer": Biomedicine \& Pharmacotherapy 111: 338-346.

30. Stefanie K Wculek, Ilaria Malanchi. "Neutrophils support lung colonization of metastasis-initiating breast cancer cells": Nature 528(7582): 413-437.

31. Suhas Vittal, Gokul Karthikeyan (2018) "Modeling association detection in order to discover compounds to inhibit oral cancer": J Biomed Inform 84: 159-163.

Copyright: (C2020 CRUZ-RODRIGUEZ Luis. This is an open-access article distributed under the terms of the Creative Commons Attribution License, which permits unrestricted use, distribution, and reproduction in any medium, provided the original author and source are credited. 